\title{
Investigation of the role of SDHB inactivation in sporadic phaeochromocytoma and neuroblastoma
}

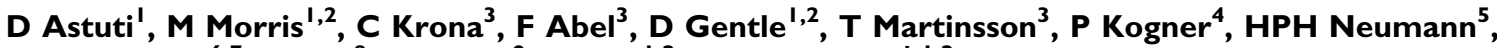

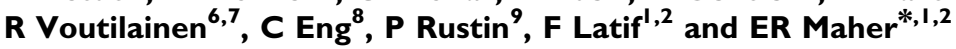

'Section of Medical and Molecular Genetics, Department of Paediatrics and Child Health, University of Birmingham, The Medical School, Edgbaston, Birmingham BI 5 2TT, UK; ${ }^{2}$ Cancer Research UK Renal Molecular Oncology Research Group, University of Birmingham, The Medical School, Edgbaston, Birmingham BI5 2TT, UK; ${ }^{3}$ Department of Clinical Genetics, Gothenburg University, Sahlgrenska University Hospital/Ostra, S-4 I6 85 Gothenburg, Sweden; ${ }^{4}$ Childhood Cancer Research Unit, Department of Woman and Child Health, Karolinska Institute, Karolinska Hospital, S-I7I 76 Stockholm, Sweden; ${ }^{5}$ Medizinische Universitatsklinik, Hugstetter Str. 55, D-79 106 Freiburg, Germany; ${ }^{6}$ Department of Paediatrics, Kuopio University Hospital, FIN7021 I Kuopio, Finland; ${ }^{7}$ Department of Pathology, Haartman-Institute, FIN-000 I 4 University of Helsinki, Helsinki, Finland; ${ }^{8}$ Clinical Cancer Genetics and Human Cancer Genetics Programs, Comprehensive Cancer Center, the Division of Human Genetics, Department of Internal Medicine, The Ohio State University, Columbus, OH, USA; ${ }^{9}$ INSERM U393 Handicaps Génétique de l'Enfant, Hôpital Necker-Enfants Malades, 149 , rue de Sèvres, 75015 Paris, France

Germline mutations in the succinate dehydrogenase $(\mathrm{SDH})$ (mitochondrial respiratory chain complex II) subunit B gene, SDHB, cause susceptibility to head and neck paraganglioma and phaeochromocytoma. Previously, we did not identify somatic SDHB mutations in sporadic phaeochromocytoma, but SDHB maps to I 336 , a region of frequent loss of heterozygosity $(\mathrm{LOH})$ in neuroblastoma as well. Hence, to evaluate SDHB as a candidate neuroblastoma tumour suppressor gene (TSG) we performed mutation analysis in 46 primary neuroblastomas by direct sequencing, but did not identify germline or somatic SDHB mutations. As TSGs such as RASSFIA are frequently inactivated by promoter region hypermethylation, we designed a methylation-sensitive PCR-based assay to detect SDHB promoter region methylation. In 21\% of primary neuroblastomas and 32\% of phaeochromocytomas (32\%) methylated (and unmethylated) alleles were detected. Although promoter region methylation was also detected in two neuroblastoma cell lines, this was not associated with silencing of SDHB expression, and treatment with a demethylating agent (5-azacytidine) did not increase $\mathrm{SDH}$ activity. These findings suggest that although germline SDHB mutations are an important cause of phaeochromocytoma susceptibility, somatic inactivation of SDHB does not have a major role in sporadic neural crest tumours and SDHB is not the target of I p36 allele loss in neuroblastoma and phaeochromocytoma.

British Journal of Cancer (2004) 91, 1835-184I. doi:10.1038/sj.bjc.6602202 www.bjcancer.com

Published online 26 October 2004

(c) 2004 Cancer Research UK

Keywords: SDHB; methylation; neuroblastoma; phaeochromocytoma

Neuroblastoma and phaeochromocytoma are the most common neural crest-derived tumours in children and adults, respectively. Neuroblastoma is clinically variable with some tumours demonstrating spontaneous regression after little or no therapy, while in other cases distant metastases are present at diagnosis. Familial neuroblastoma is rare and major susceptibility genes have not yet been isolated. Phaeochromocytomas usually present with hypertension and $90 \%$ are benign. Germline mutations in the RET, VHL, $S D H B$ and $S D H D$ genes are important causes of phaeochromocytoma susceptibility and phaeochromocytoma may also rarely $(<1 \%)$ complicate neurofibromatosis type 1 (reviewed by Maher and Eng 2002, Eng et al, 2003). Human cancer genetics provides many examples of how the identification of a rare inherited cancer susceptibility gene has provided insights into the pathogenesis of

*Correspondence: Professor ER Maher; E-mail: E.R.Maher@bham.ac.uk Received 10 May 2004; revised 31 August 2004; accepted 2 September 2004; published online 26 October 2004 sporadic cases. However, exceptions exist: although von HippelLindau disease is a major cause of familial clear cell renal carcinoma (cRCC) and somatic inactivation of the VHL tumour suppressor gene (TSG) occurs in most sporadic cRCC (Gnarra et al, 1994; Foster et al, 1994; Herman et al, 1994; Clifford et al, 1998), somatic VHL inactivation by mutation or methylation of the promoter region is infrequent $(<5 \%)$ in sporadic phaeochromocytomas. In addition, although both phaeochromocytoma and medullary thyroid cancer are major features of MEN 2A and MEN 2B and somatic RET mutations are common in sporadic medullary thyroid cancer (Eng et al, 1994, 1995), somatic RET mutations are found in only $10 \%$ of sporadic phaeochromocytomas (Eng et al, 1995; Hofstra et al, 1996). Thus, VHL and RET appear to have only a minor role in the pathogenesis of sporadic phaeochromocytoma.

The SDHB and SDHD genes encode two (of four) subunits of the mitochondrial respiratory chain complex II (succinate dehydrogenase: SDH). Germline mutations in $S D H B$ and $S D H D$, in addition to causing phaeochromocytoma, may also predispose to the development of head and neck paragangliomas (most commonly 
carotid body tumours) (Baysal et al, 2000; Gimm et al 2000, Astuti et al, 2001a, b, 2003; Gimenez-Roqueplo et al, 2002; Neumann et al, 2002, Benn et al, 2003; Leube et al, 2004). Familial phaeochromocytoma or head and neck paraganglioma (HNPGL) kindreds with germline $S D H D$ mutations demonstrate parent-of-origin effects on penetrance (Baysal et al, 2000; Astuti et al, 2001a). In contrast, $S D H B$ mutations show no evidence of genomic imprinting effect. $S D H B$ maps to $1 \mathrm{p} 36$, a region of frequent allele loss in many tumour types including neuroblastoma and phaeochromocytoma (Martinsson et al, 1997; Maris and Matthay, 1999; Benn et al, 2000; Ejeskar et al, 2001). Previously, we did not detect somatic SDHB mutations in 24 sporadic phaeochromocytomas (Astuti et al, 2001b) and this has been confirmed by others (Benn et al, 2003). However, studies of a number of TSGs have established a paradigm in which specific TSGs can be inactivated frequently by de novo promoter methylation but rarely by somatic mutations (Dammann et al, 2000; Agathanggelou et al, 2001; Burbee et al, 2001; Morrissey et al, 2001). In keeping with this, we have reported frequent RASSF1A hypermethylation in neuroblastoma and phaeochromocytoma (Astuti et al, 2001c). These findings prompted us to investigate whether $S D H B$ promoter methylation occurred in neuroblastoma and phaeochromocytoma.

\section{MATERIALS AND METHODS}

\section{Clinical material}

DNA were extracted from frozen primary tumour tissue from (a) 35 sporadic phaeochromocytomas without evidence of germline or somatic $S D H B$ mutations (four tumours were from patients with von Hippel - Lindau disease and three from patients with MEN2A) and one phaeochromocytoma with a germline $S D H B$ mutation was analysed (Astuti et al, 2001b); (b) 46 neuroblastomas and (c) from corresponding normal tissue samples (fibroblast or blood) were analysed. Approval from the appropriate Institutional Review Boards and informed consent from all patients were obtained. Most of this tumour material has been described earlier (Martinsson et al, 1997; Ejeskär et al, 1998; Astuti et al, 2001c).

\section{Bisulphite modification and methylation-specific PCR (MSP)}

Bisulphite DNA modification was performed as described previously (Herman et al, 1996). Briefly, $0.5-1.0 \mu \mathrm{g}$ of genomic DNA was denatured in $0.3 \mathrm{M} \mathrm{NaOH}$ for $15 \mathrm{~min}$ at $37^{\circ} \mathrm{C}$ and then unmethylated cytosine residues were sulphonated by incubation in $3.12 \mathrm{M}$ sodium bisulphite ( $\mathrm{pH}$ 5.0) (Sigma) $5 \mathrm{~mm}$ hydroquinone (Sigma) in a thermocycler (Hybaid) for $30 \mathrm{~s}$ at $99^{\circ} \mathrm{C} / 15 \mathrm{~min}$ at $50^{\circ} \mathrm{C}$ for 20 cycles. The sulphonated DNA was recovered using the Wizard DNA clean-up system (Promega) in accordance with the manufacturer's instructions. The conversion reaction was completed by desulphonating in $0.3 \mathrm{M} \mathrm{NaOH}$ for $10 \mathrm{~min}$ at room temperature. The DNA was ethanol precipitated and resuspended in water. Methylation-specific PCR was performed using specific primers designed to amplify methylated and unmethylated putative SDHB promoter sequences (Au et al, 1995; GeneBank accession No. U17296): unmethylated - specific, 5'-TGTGTTGTTA TTGTGTTATTGTGTAT-3' (forward) and $5^{\prime}$-CCACCAAAAATTA TAACCAACAACCA-3' (reverse) and methylated - specific, $5^{\prime}$-TGCG TCGTTATTGCGTTATTGCGTAC-3' (forward) and 5'-CCGCCAAA AATTATAACCGACAACCG-3' (reverse) (Figure 1). Taq DNA polymerase (Gibco) was added after a 'hot start' at $95^{\circ} \mathrm{C}$ for 5 min. Amplification was carried out for 35 cycles at an annealing temperature of $53^{\circ} \mathrm{C}$ for the unmethylated specific primers and $61^{\circ} \mathrm{C}$ for the methylated specific primers on Omn-E (Hybaid) DNA thermal cycler. The expected sizes of the PCR products for both unmethylated and methylation-specific amplifications were $269 \mathrm{bp}$.

\section{Cloning and sequencing of PCR products}

The PCR products containing bisulphite-resistant cytosines were purified using PCR product purification kit (Qiagen) and ligated into the pGEM-T easy vector system (Promega), according to the manufacturer's instructions. Several clones were then isolated and sequenced using ABI 377 DNA analyser (Applied Biosystem).

Mutation analysis $S D H B$ mutation analysis was performed by direct sequencing of coding sequence amplicons as previously described (Astuti et al, 2001b). The GenBank accession number for SDHB exons $1-8$ are: U17296, U17880, U17881, U17882, U17883, U17884, U17885 and U17886. Sequence analysis was performed on an ABI PRISM 3100 DNA Sequencer (Applied Biosystems). The sequencing products were compared to the $S D H B$ reference sequence NM_003000.

\section{Cell culture and Western blot analysis}

Two neuroblastoma cell lines (SK-N-AS and SK-N-SH) purchased from ATCC were grown in Dulbecco's modified eagle medium, supplemented with $10 \%$ foetal calf serum. Demethylation was performed by the addition of $2 \mu \mathrm{M} \mathrm{5-aza-2-deoxycytidine} \mathrm{to} \mathrm{the}$ growth medium. This latter was replenished with fresh medium after 3 days. On the fifth day of treatment, total protein was extracted in NETS lysis buffer $(150 \mathrm{~mm} \mathrm{NaCl}, 50 \mathrm{~mm}$ Tris ( $\mathrm{pH} 8)$ $5 \mathrm{~mm}$ EDTA, $1 \%$ NP40) containing $3 \mathrm{~mm} \mathrm{PMSF,} 20 \mu \mathrm{g} \mathrm{ml}^{-1}$ aprotonin and $10 \mu \mathrm{g} \mathrm{ml}^{-1}$ leupeptin. Following homogenisation and incubation on ice for $10 \mathrm{~min}$, lysates were centrifuged for $15 \mathrm{~min}$ at $14000 \mathrm{rpm} / 4^{\circ} \mathrm{C}$ and stored at $-20^{\circ} \mathrm{C}$.

Protein samples (20 $\mu \mathrm{g}$ each) were separated on sodium dodecyl sulphate-10.5\% polyacrylamide gel and electroblotted to transblot polyvinylidene difluoride membrane (Hybond-P; Amersham Bioscience, Chalfont St Giles, UK). Anti-SDHB (Molecular Probes, clone: $21 \mathrm{~A} 11-\mathrm{AE} 7)$ at $2.5 \mu \mathrm{g} \mathrm{ml}^{-1}$ was applied followed by rabbit anti-mouse immunoglobulin-peroxidase conjugate. Visualisation was carried out by the enhanced chemiluminescence detection system (ECL-plus; Amersham Bioscience). The filter

\section{SDHB-MS-F}

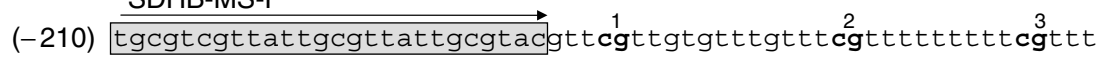

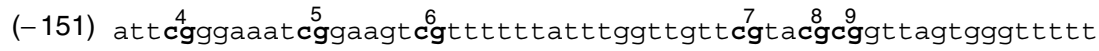

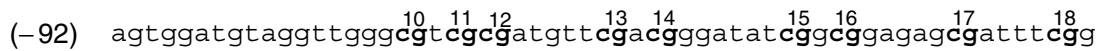

(-33) ggttaaggggtggggttgacgttaggagttaagatglgcggcggtggtcotttttttt

(+27) gaggeg 23 cggttgtcggttataattttggcgg

SDHB-MS-R

Figure I SDHB promoter sequence. In boxes shaded in light grey are the MSP primer sequences. CpG islands are in bold and numbered from I to 23 . The numbers in brackets are nucleotide position in relation to the ATG start codon (highlighted in light grey). 
was stained with India ink for standardisation, and quantification was performed using a Bio-Rad imaging densitometer with Quantity One software.

Enzyme assays Succinate cytochrome $c$ reductase (complex II and III) and quinol cytochrome $c$ reductase (complex III) activities were spectrophotometrically measured in neuroblastoma cell line homogenates as previously described (Rustin et al, 1994).

\section{Loss of heterozygosity (LOH) analysis}

Assessment of neuroblastoma samples for $1 \mathrm{p}$ loss of heterozygosity (LOH) has been reported previously (Martinsson et al, 1995, 1997; Ejeskär et al, 2001). The 1p allele status of the phaeochromocytoma samples was investigated using a panel of 14 polymorphic microsatellite markers, including 1pter-D1S243, D1S1646, D1S1635, D1S434, D1S1597, D1S228, D1S552, D1S1676, D1S1622, D1S2134, D1S1661, D1S1596, D1S551 and D1S435-1cen. Primer sequences are available from the Genome Database (http:// gdbwww.gdb.org). The PCR products were electrophoresed on an $8 \%$ urea - polyacrylamide gel and were visualised by silver staining. Allelic loss was considered to have occurred in tumour samples when there was a $50 \%$ or greater reduction in signal intensity of an allele in tumour DNA compared to normal DNA.

Statistical analysis Comparisons were made by Fisher's exact test (two tailed). $P$-values of 0.05 were taken as statistically significant.

\section{RESULTS}

\section{$S D H B$ methylation and mutation status in neuroblastoma}

Direct sequencing of the $S D H B$ coding exons and flanking sequences in 46 neuroblastoma tumours was performed. No pathogenic mutations were detected, although a number of known sequence variants and deviations from reference sequence were detected. One silent heterozygous SNP $(18 \mathrm{~A}>\mathrm{C})$ was identified in a stage 4 neuroblastoma with a fatal outcome of the disease. Some variations from the reference sequence (c.-16delG, IVS3-(18-19) insA, IVS3-(24-25)insA, IVS7 + 4delA, and IVS8 + (19-20)insT) were present in homozygous form in all samples including the control, and they are thus likely to be errors in the reference sequence. A trinucleotide repeat, $\mathrm{TTC}_{\mathrm{n}}$, with the most $3^{\prime}$ nucleotide located 14 bases upstream of exon 5 was found to be polymorphic. The number of repeats varied between 6 and 10 with 8 repetitions being the most common allele. Of 94 neuroblastoma tumour samples tested, 91 were homozygous (or hemizygous) $\mathrm{TTC}_{8}$ compared to 98 out of 99 control samples.

$S D H B$ promoter methylation status was investigated in 46 primary neuroblastoma tumours. In all, $22 \%$ (10 out of 46 ) of the neuroblastomas demonstrated $S D H B$ CpG island promoter methylation by MSP analysis compared to 0 of 20 normal control blood samples. Sequencing of the MSP product (10 individual clones from two methylated tumours) demonstrated that 22 of the $23 \mathrm{CpG}$ dinucleotides in the fragment were methylated in each tumour (Figure 2). In each tumour with SDHB methylation, unmethylated alleles were also detected so there was no evidence of complete methylation. There was no significant difference between the frequency of $S D H B$ promoter methylation in neuroblastoma tumours with and without 1p36 allele loss and no correlation with $3 \mathrm{p}$ allele loss, $17 \mathrm{q}$ gain or $\mathrm{N}-\mathrm{myc}$ amplification status. Furthermore, there was no association between partial $S D H B$ promoter methylation and tumour stage ( $21 \%$ of stage 1,2 and $4 \mathrm{~S}$ tumours, and in $27 \%$ of stage 3 and 4 tumours).

\section{1 pLOH analysis and $S D H B$ promoter methylation in sporadic phaeochromocytomas}

Previously we did not find evidence of somatic $S D H B$ mutations in sporadic phaeochromocytomas (Astuti et al, 2001b). However, to investigate further the potential role of $S D H B$ in the pathogenesis of phaeochromocytoma, we determined the frequency, extent and patterns of $1 \mathrm{p}$ allele loss in 36 sporadic phaeochromocytomas using 14 polymorphic microsatellite markers mapping to $1 \mathrm{p} 22-$ 1p36. In all, $75 \%(27 / 36)$ of tumours demonstrated LOH at one or more $1 \mathrm{p}$ locus (Figure 3). A total of 10 tumours demonstrated LOH

A

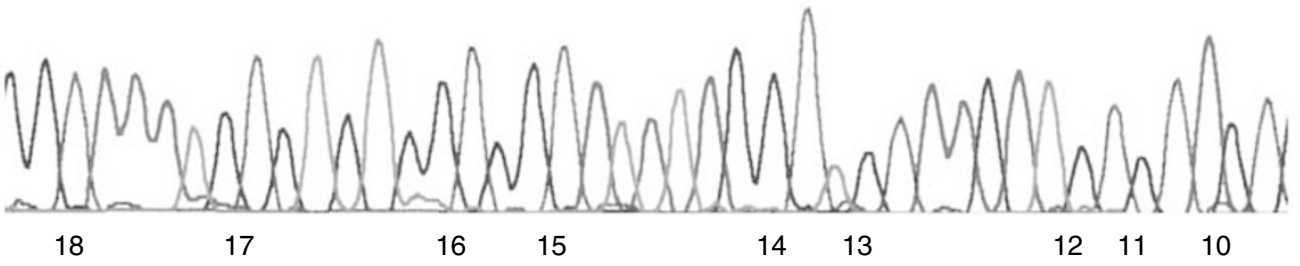

B
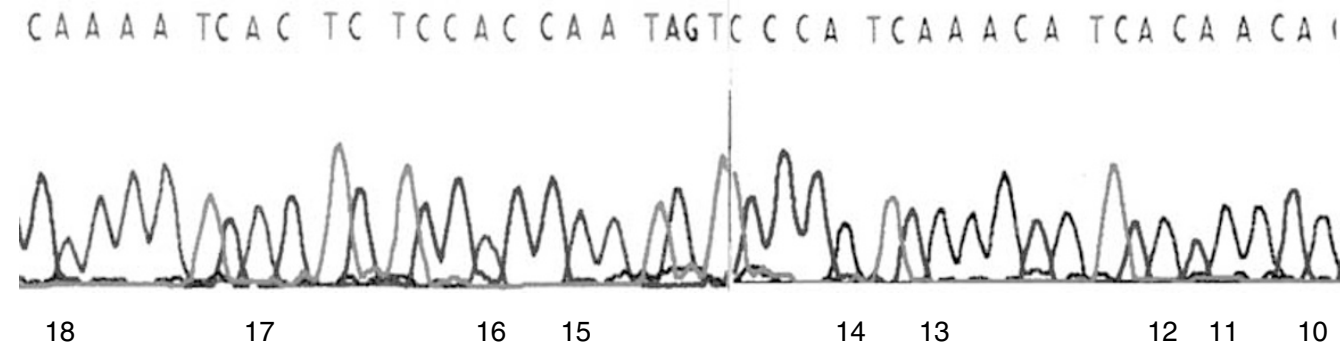

Figure 2 (A) Partial chromatogram of cloned MSP product from a methylated neuroblastoma tumour (St I 58T). Methylated cytosine appear as a G signal in the complementary strand. The number indicates the position of $\mathrm{CpG}$ sites. (B) Similar chromatogram obtained from an unmethylated neuroblastoma tumour (StI I IT). 


\begin{tabular}{|c|c|c|c|c|c|c|c|c|c|c|c|c|c|c|c|c|c|c|c|c|c|c|c|c|c|c|c|c|c|c|c|c|c|c|c|c|c|}
\hline \multirow{2}{*}{\multicolumn{2}{|c|}{$\begin{array}{l}\text { Location } \\
\text { (Mb from pter) }\end{array}$}} & \multirow{2}{*}{ Marker } & \multicolumn{35}{|c|}{ Tumor } \\
\hline & & & $F$ & $\cong$ & $\stackrel{m}{\mapsto}$ & $\stackrel{\rightleftarrows}{\vdash}$ & $\stackrel{\rho}{\llcorner}$ & 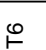 & $\vDash \stackrel{\infty}{\vdash}$ & 0 & 음 & $T$ & $\stackrel{N}{F}$ & 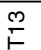 & $\underset{F}{\stackrel{\nabla}{F}}$ & $\stackrel{\llcorner}{F}$ & $\stackrel{\varphi}{F}$ & $\underline{F}$ & $\stackrel{\infty}{F}$ & $\stackrel{\sigma}{F}$ & $\stackrel{\text { }}{\vdash}$ & $\overline{\mathfrak{N}}$ & $\stackrel{N}{\mathfrak{N}}$ & $\stackrel{\mathfrak{N}}{\mathfrak{N}}$ & $\stackrel{\mathbb{I}}{\stackrel{4}{ }}$ & $\stackrel{\llcorner}{\stackrel{N}{\curvearrowleft}}$ & 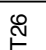 & $\hat{N}$ & $\stackrel{\infty}{\sim}$ & $\stackrel{\mathbb{N}}{\leftarrow}$ & 옴 & $\bar{m}$ & ల్ల & m & 岕 & $\stackrel{m}{\circ}$ & ழ్ల \\
\hline & 1.9 & $1 S 243$ & & - & ○ & ○ & $\bullet$ & 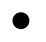 & 0 & 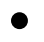 & 0 & 0 & 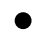 & P & 0 & 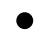 & • & 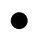 & - & 0 & 0 & - & 0 & 0 & 0 & 0 & 0 & 0 & 0 & 0 & 0 & 0 & 0 & 0 & 0 & 0 & 0 \\
\hline & 6.7 & D1S1646 & ? & $\Omega$ & O & $\bullet$ & $\bullet$ & $\bullet$ & 0 & 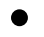 & 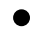 & $\bullet$ & 0 & 0 & 0 & $\bullet$ & - & • & - & - & 0 & 0 & 0 & 0 & 0 & 0 & 0 & 0 & 0 & 0 & 0 & 0 & 0 & 0 & 0 & O & 0 \\
\hline & 10.6 & D1S1635 & $\bullet$ & $\bullet$ & - & $\bullet$ & 0 & 0 & 0 & - & $\bullet$ & $\bullet$ & $\bullet$ & 0 & $\bullet$ & $\bullet$ & $\bullet$ & $\bullet$ & $\bullet$ & 0 & 0 & 0 & 0 & 0 & 0 & 0 & 0 & 0 & 0 & 0 & 0 & 0 & 0 & 0 & 0 & O & 0 \\
\hline & 11. & $1 S 434$ & 0 & O & 0 & 0 & ○ & 0 & 0 & • & 0 & 0 & 0 & $\bullet$ & 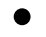 & 0 & • & $\bullet$ & 0 & - & - & 0 & 0 & 0 & 0 & 0 & 0 & 0 & 0 & 0 & 0 & 0 & 0 & 0 & 0 & O & 0 \\
\hline & 13.0 & D1S1597 & 0 & - & - & 0 & $\bullet$ & $\bullet$ & 0 & - & $\bullet$ & $\bullet$ & $\bullet$ & 0 & • & $\bullet$ & 0 & $\bullet$ & 0 & - & 0 & 0 & 0 & 0 & 0 & 0 & 0 & 0 & 0 & 0 & 0 & 0 & 0 & 0 & 0 & O & 0 \\
\hline & -13.2 & D1S & 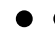 & ? & 0 & - & $\bullet$ & $\bullet$ & 0 & $\bullet$ & $\bullet$ & $\bullet$ & . & $\bullet$ & 0 & O & 0 & 0 & 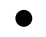 & 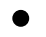 & $\bullet$ & 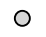 & 0 & 0 & 0 & 0 & 0 & 0 & 0 & 0 & 0 & O & 0 & 0 & 0 & 0 & 0 \\
\hline & -18. & D1S552 & • & O & • & 0 & • & 0 & $\bullet$ & • & • & O & • & • & e & • & 0 & • & $\bullet$ & $\bullet$ & O & 0 & $\bullet$ & O & O & 0 & • & 0 & O & 0 & O & O & 0 & 0 & 0 & 0 & 0 \\
\hline & 24.6 & D1S1676 & & O & - & 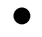 & 0 & 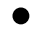 & ค & - & 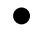 & $\bullet$ & 0 & 0 & 0 & $\bullet$ & ○ & $\bullet$ & 0 & • & $\bullet$ & 0 & $\bullet$ & $\bullet$ & 0 & 0 & 0 & 0 & 0 & 0 & 0 & 0 & 0 & 0 & 0 & O & 0 \\
\hline & 29. & D1S & 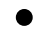 & 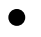 & 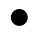 & 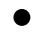 & 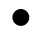 & 0 & 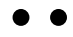 & $\bullet$ & 0 & $\bullet$ & 0 & $\bullet$ & 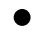 & $\bullet$ & 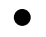 & $\bullet$ & 0 & 0 & 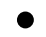 & 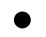 & $\bullet$ & $\bullet$ & 0 & 0 & 0 & 0 & 0 & 0 & 0 & 0 & 0 & 0 & 0 & O & 0 \\
\hline & 47 & D1S2134 & 0 & 0 & - & - & 0 & - & 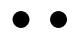 & $\bullet$ & 0 & 0 & 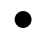 & 0 & - & 0 & $\bullet$ & • & 0 & O & - & 0 & 0 & 0 & 0 & 0 & 0 & 0 & O & 0 & 0 & O & 0 & O & 0 & O & 0 \\
\hline & 50 & D1S1661 & 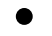 & 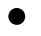 & 0 & 0 & 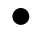 & 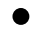 & 0 & 0 & 0 & $\bullet$ & 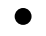 & 0 & 0 & 0 & 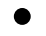 & 0 & 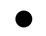 & - & • & 0 & 0 & & 0 & - & 0 & 0 & 0 & 0 & 0 & 0 & 0 & 0 & 0 & O & 0 \\
\hline & 59. & D1S1596 & 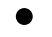 & 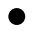 & 0 & 0 & 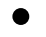 & 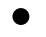 & & 0 & 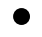 & $\bullet$ & 0 & $\bullet$ & 0 & 0 & 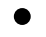 & 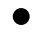 & 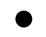 & $\bullet$ & 0 & 0 & & - & 0 & $\bullet$ & 0 & 0 & 0 & 0 & 0 & 0 & 0 & 0 & 0 & 0 & 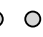 \\
\hline & 82. & D1S551 & & - & 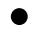 & 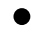 & 0 & 0 & 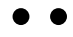 & 0 & 0 & • & 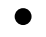 & 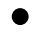 & - & 0 & $\bullet$ & - & 0 & 0 & D & 0 & ๑ & • & ح & O & 0 & 0 & O & 0 & 0 & 0 & 0 & 0 & 0 & 0 & ) \\
\hline & 90. & D1S435 & & 0 & & & 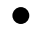 & 0 & 0 & & 0 & O & 0 & D & & & 0 & - & 0 & $\bullet$ & 0 & & ○ & 0 & - & 0 & 0 & כ & 0 & $D$ & 0 & 0 & 0 & 0 & 0 & & \\
\hline
\end{tabular}

Figure 3 Summary of chromosome Ip loss of heterozygosity analysis in phaeochromocytomas. Filled circles indicate LOH; shaded circles indicate retention of heterozygosity and open circles indicate noninformative cases. Microsatellite markers are ordered from telomere to centromere (Genome Browser-Human assembly, July 2003; http://genome.ucsc.edu).

at all informative markers and nine demonstrated retention at all informative markers. SDHB maps between D1S228 and D1S552 ( $\sim 1.7 \mathrm{MB}$ from D1S552) and LOH was observed in 54 and $64 \%$, respectively, of informative tumours at these flanking markers. A phaeochromocytoma sample with a germline $S D H B$ mutation demonstrated $1 \mathrm{p}$ allele loss (and no methylation, T12 - see later) consistent with a 'two hits' model of tumourigenesis.

$S D H B$ promoter methylation was detected in nine out of 28 (32\%) of phaeochromocytomas analysed by MSP (all matching blood DNA samples were unmethylated) (Figure 4). In addition to methylation-specific PCR products, unmethylated-specific products were also amplified from each of the nine 'methylated tumours' consistent with partial methylation in tumours and/or the presence of contaminating normal tissue in the tumour samples. Sequencing of the MSP product (10 individual clones from each of two methylated phaeochromocytomas) demonstrated methylation at 21 of the $23 \mathrm{CpGs}$ analysed (data not shown). There was no difference between the frequency of $\mathrm{LOH}$ close to $S D H B$ in phaeochromocytoma with and without $S D H B$ promoter methylation (75 vs $57 \%$ respectively, $P=0.42$ ).

\section{Functional significance of $S D H B$ promoter region methylation}

To investigate the possible functional significance of this partial promoter methylation, we screened eight neuroblastoma cell lines and identified two (SK-N-SH and SK-N-AS) with partial SDHB methylation by MSP. We then treated these two cell lines with the

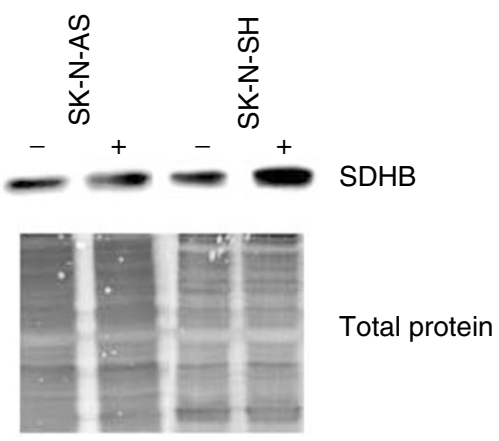

Figure 5 Expression analysis of $S D H B$ gene in neuroblastoma cell line SK-N-AS and SK-N-SH, before ( - ) and after (+) 5 aza-2-deoxycytidine treatment. Western blotting was performed essentially as described in the Material and Methods. Indian ink staining was included as a loading control.

demethylating agent, 5-azacytidine, for 5 days and evaluated the effect on $S D H B$ protein expression. Before treatment, SDHB was readily detectable and following treatment with 5-azacytidine, there were small increases in $S D H B$ protein expression (SDHB protein (up to three- and two-fold in SK-N-SH and SK-N-AS cells respectively) (Figure 5). However, the relatively small changes in SDHB expression were not associated with evidence of enhanced SDH enzyme activity. Thus, the ratio of quinol cytochrome $c$ reductase (complex III) (QCCR) to succinate cytochrome $c$ 
reductase (complex II and III) (SCCR) enzyme activities was not abnormally increased prior to treatment with 5-aza-2-deoxycytidine, and there was no reduction in QCCR/SCCR ratio after demethylation (SK-N-SH cell line: Pretreatment QCCR/SCCR ratio $=2.13$, post-treatment 3.7; SK-N-AS cell line, pretreatment QCCR/SCCR ratio $=2.85$, post-treatment 3.44 ; controls (lymphoblastoid cell lines: QCCR/SCCR ration $=3.1 \pm 0.3$ ).

\section{DISCUSSION}

Neuroblastomas and phaeochromocytomas are the most common neural crest-derived tumours in children and adults, respectively, and it is of interest to compare the molecular pathology of the two tumours. The molecular pathology of sporadic neuroblastomas has been investigated extensively. Frequent alterations include $\mathrm{N}$-myc amplification $(20-25 \%)$ and gain of genetic material at $17 q 23-$ qter ( $-50 \%$ of tumours). Neuroblastoma suppressor genes have been mapped by $\mathrm{LOH}$ studies to $1 \mathrm{p} 36(30-35 \%$ of primary tumours show LOH), 11q23 (44\%) and 14q231 - qter (22\%) (reviewed in Maris and Matthay, 1999). In addition to these welldefined genetic alterations, we and others have demonstrated that epigenetic TSG inactivation may be a feature of neuroblastoma. Thus, CASP8 promoter methylation has been reported in $\sim 50 \%$ of neuroblastomas by us and other (Teitz et al, 2000; Astuti et al, 2001c; Harada et al, 2002a) and RASSF1A promoter methylation also occurs frequently (52-55\% (Astuti et al, 2001c; Harada et al, $2002 \mathrm{~b})$. However, Harada et al (2002b) detected no or little promoter methylation of $p 16^{I N K 4 A}(0 \%), M G M T(0 \%), R A R B(0 \%)$, DAPK (0\%), APC (0\%), CDH13 (0\%), CDH1 (6\%) and GSTP1 (3\%) in primary neuroblastoma tumours. These genes have all demonstrated promoter methylation in other cancer types and so most TSGs analysed to date do not show promoter methylation in neuroblastoma.

Although there is compelling evidence for a major neuroblastoma suppressor gene on $1 \mathrm{p}$, to date, a major $1 \mathrm{p} 36.2$ - p36.3 neuroblastoma suppressor gene has not been identified (Ejeskär et al, 1999; Jogi et al, 2000; Abel et al, 2002). We did not detect somatic SDHB gene mutations in neuroblastoma and we could not demonstrate evidence for epigenetic inactivation. In addition, we note that the critical neuroblastoma suppressor gene interval defined by Ejeskar et al (2001) (D1S508 to D1S244) and the $500 \mathrm{~kb}$ 1 p36.2 - p36.3 homozygous deletion in a neuroblastoma cell line reported by Ohira et al (2000), both map $>4 \mathrm{Mb}$ telomeric to SDHB. CASP8 and RASSF1A methylation in neuroblastoma is associated with transcriptional downregulation, but in contrast $S D H B$ promoter methylation did not impair SDH enzyme activity. We note that despite tumour-specific WT1 promoter methylation in primary breast cancer, WT1 protein is still expressed in these tumours (Loeb et al, 2001). While MSP provides a sensitive technique for detecting promoter methylation in tumour samples, the ability to detect low levels of methylation, in only a subset of tumour cells, can exaggerate the frequency of promoter methylation.

Even though germline $S D H B$ mutations are an important cause of phaeochromocytoma susceptibility (Astuti et al, 2001b; Neumann et al, 2002), we did not identify somatic SDHB mutations in phaeochromocytoma so far. Similarly, germline mutations in the VHL TSG are an important cause of phaeochromocytoma

\section{REFERENCES}

Abel F, Sjöberg RM, Ejeskär K, Krona C, Martinsson T (2002) Analyses of apoptotic regulators CASP9 and DFFA at 1P36.2, reveal rare allele variants in human neuroblastoma tumours. $\mathrm{Br} J$ Cancer 86: $596-604$

Agathanggelou A, Honorio S, Macartney DP, Martinez A, Dallol A, Rader J, Fullwood P, Chauhan A, Walker R, Shaw JA, Hosoe S, Lerman MI, Minna susceptibility, but somatic VHL mutations are rare in phaeochromocytoma (Eng et al, 1995; Woodward et al, 1997). The finding of $1 \mathrm{p} \mathrm{LOH}$ in a phaeochromocytoma with a germline $S D H B$ mutation is consistent with a two hit hypothesis of tumorigenesis and the frequent occurrence of $1 \mathrm{p} \mathrm{LOH}$ in sporadic phaeochromocytomas without $S D H B$ mutations suggested that in some cases $S D H B$ inactivation could occur by a combination of $\mathrm{LOH}$ and $S D H B$ promoter methylation. However Benn et al (2000) have suggested that there were at least two distinct intervals (three possible regions) of $1 \mathrm{p} \mathrm{LOH}$ in phaeochromocytoma. $S D H B$ maps outside the most telomeric distinct interval (PC1, D1S243 to D1S244) but is contained within the second interval (D1S228 to $>40 \mathrm{cM}$ centromeric). In our LOH studies, 10 tumours with partial $1 p$ $\mathrm{LOH}$ had no $\mathrm{LOH}$ at $\mathrm{D} 1 \mathrm{~S} 228$ but $\mathrm{LOH}$ at more centromeric markers. $S D H B$ maps $\sim 4 \mathrm{Mb}$ centromeric to D1S228 (http:// genome.ucsc.edu/cgi-bin/hgGateway) so LOH studies did not exclude $S D H B$ being implicated in phaeochromocytoma tumorigenesis. As for chromosome $3 \mathrm{p}$, multiple TSGs may map to $1 \mathrm{p}$. We note that in several tumours there were complicated patterns of $\mathrm{LOH}$ with areas of $\mathrm{LOH}$ flanking a marker with retention of heterozygosity. Such patterns may reflect the involvement of multiple TSGs in a single tumour. Although we detected evidence for partial $S D H B$ promoter methylation using the sensitive MSP technique in a subset of phaeochromocytomas, this degree of methylation did not impair SDH activity (for comparison, Gimenez-Roqueplo et al (2002) found a mean QCCR/SCCR ratio of $>200$ in phaeochromocytomas with $S D H B$ mutations and 2.7 in phaeochromocytomas without $S D H B$ mutations).

The mechanism whereby germline $S D H B$ mutations promote tumorigenesis is uncertain. $S D H B$ inactivation may lead to upregulation of a wide range of hypoxia-inducible genes (Gimenez-Roqueplo et al, 2002). Activation of hypoxia-responsive pathways may have an important role in cancer development and may be caused by local tissue hypoxia or result from genetic mechanisms (An et al, 1998; Maxwell et al, 1999; Zundel et al, 2000). However, germline VHL mutations that cause phaeochromocytomas and not other features of VHL disease retain the ability to regulate hypoxia-inducible factor HIF-1 and HIF-2 (Clifford et al, 2001; Hoffman et al, 2001). Mitochondrial dysfunction may reduce apoptosis and promote tumorigenesis (Green and Reed, 1998), and is another mechanism by which $S D H B$ inactivation could promote tumorigenesis. Further work is required to define the precise mechanism of $S D H B$ tumour suppression and how these explain the restricted phenotype of $S D H B$-associated tumours and the lack of evidence for a role of somatic $S D H B$ inactivation in the pathogenesis of sporadic phaeochromocytomas.

\section{ACKNOWLEDGEMENTS}

This work is supported by the British Heart Foundation (DA, FL, EM), Cancer Research UK (MM, FL, EM), Swedish Cancer Society, Swedish Children's Cancer Foundation (TM, PK), Deutsche Forchungsgemeinschaft Grant NE 571/5-2 and the Deutsche Krebshilfe Grant 70-3313-Ne 1 (HPH) and P30CA16058 from the National Cancer Institute, Bethesda, MD, USA (to The Ohio State University Comprehensive Cancer Center). CE is a recipient of the Doris Duke Distinguished Clinical Scientist Award.

JD, Maher ER, Latif F (2001) Methylation associated inactivation of RASSF1A from region $3 \mathrm{p} 21.3$ in lung, breast and ovarian tumours. Oncogene 20: 1509-1518

An WG, Kanekal M, Simon MC, Maltepe E, Blagosklonny MV, Neckers LM (1998) Stabilization of wild-type $\mathrm{p} 53$ by hypoxia-inducible factor 1alpha. Nature 392: $405-408$ 
Astuti D, Douglas F, Lennard TW, Aligianis IA, Woodward ER, Evans DG, Eng C, Latif F, Maher ER (2001a) Germline SDHD mutation in familial phaeochromocytoma. Lancet 357: 1181-1182

Astuti D, Latif F, Dallol A, Dahia PL, Douglas F, George E, Skoldberg F, Husebye ES, Eng C, Maher ER (2001b) Gene mutations in the succinate dehydrogenase subunit SDHB cause susceptibility to familial pheochromocytoma and to familial paraganglioma. Am J Hum Genet 69: $49-54$

Astuti D, Agathanggelou A, Honorio S, Dallol A, Martinsson T, Kogner P, Cummins C, Neumann HPH, Voutilainen R, Dahia P, Eng C, Maher ER, Latif F (2001c) RASSF1A promoter region CpG island hypermethylation in phaeochromocytomas and neuroblastoma tumours. Oncogene 20: $7573-7577$

Astuti D, Hart-Holden N, Latif F, Lalloo F, Black GC, Lim C, Moran A, Grossman AB, Hodgson SV, Freemont A, Ramsden R, Eng C, Evan DG, Maher ER (2003) Genetic analysis of mitochondrial complex II subunits SDHD, SDHB and SDHC in paraganglioma and phaeochromocytoma susceptibility. Clin Endocrinol 59: 728-733

$\mathrm{Au}$ HC, Ream-Robinson D, Bellew LA, Broomfield PLE, Saghbini M, Scheffler IE (1995) Structural organization of the gene encoding the human iron-sulfur subunit of succinate dehydrogenase. Gene 159: $249-253$

Baysal BE, Ferrell RE, Willett-Brozick JE, Lawrence EC, Myssiorek D, Bosch A, van der Mey A, Taschner PE, Rubinstein WS, Myers EN, Richard III CW, Cornelisse CJ, Devilee P, Devlin B (2000) Mutations in SDHD, a mitochondrial complex II gene, in hereditary paraganglioma. Science 287: $848-851$

Benn DE, Dwight T, Richardson AL, Delbridge L, Bambach CP, Stowasser M, Gordon RD, Marsh DJ, Robinson BG (2000) Sporadic and familial pheochromocytomas are associated with loss of at least two discrete intervals on chromosome 1p. Cancer Res 60: 7048-7051

Benn DE, Croxson MS, Tucker K, Bambach CP, Richardson AL, Delbridge L, Pullan PT, Hammond J, Marsh DJ, Robinson BG (2003) Novel succinate dehydrogenase subunit B (SDHB) mutations in familial phaeochromocytomas and paragangliomas, but an absence of somatic SDHB mutations in sporadic phaeochromocytomas. Oncogene 22: $1358-1364$

Burbee DG, Forgacs E, Zöchbauer-Müller S, Shivakumar L, Gao B, Randle D, Virmani A, Bader S, Sekido Y, Latif F, Fong K, Gazdar AF, Lerman MI, White M, Minna JD (2001) Epigenetic inactivation of RASSF1A in lung and breast cancers and malignant phenotype suppression. J Natl Cancer Inst 93: 691-699

Clifford SC, Prowse AH, Affara NA, Buys CHCM, Maher ER (1998) Inactivation of the von Hippel-Lindau (VHL) tumour suppressor gene and allelic losses at chromosome arm $3 p$ in primary renal cell carcinoma: evidence for a VHL-independent pathway in clear cell renal tumourigenesis. Gene Chromosome Cancer 22: 200-209

Clifford SC, Cockman ME, Smallwood AC, Mole DR, Woodward ER, Maxwell PH, Ratcliffe PJ, Maher ER (2001) Contrasting effects on HIFlalpha regulation by disease-causing pVHL mutations correlate with patterns of tumourigenesis in von Hippel-Lindau disease. Hum $\mathrm{Mol}$ Genet 10: 1029-1038

Dammann R, Li C, Yoon JH, Chin PL, Bates S, Pfeifer GP (2000) Epigenetic inactivation of a RAS association domain family protein from the lung tumour suppressor locus 3p21.3. Nat Genet 25: 315-319

Ejeskär K, Sjöberg RM, Abel F, Kogner P, Ambros PF, Martinsson T (2001) Fine mapping of a tumour suppressor candidate gene region in $1 \mathrm{p} 36.2-$ 3 , commonly deleted in neuroblastomas and germ cell tumours. Med Pediatr Oncol 36: 61-66

Ejeskär K, Sjöberg RM, Kogner P, Martinsson T (1999) Variable expression and absence of mutations in p73 in primary neuroblastoma tumors argues against a role in neuroblastoma development. Int J Mol Med 3: $585-589$

Ejeskär K, Aburatani H, Abrahamsson J, Kogner P, Martinsson T (1998) Loss of heterozygosity of $3 \mathrm{p}$ markers in neuroblastoma tumours implicate a tumour-suppressor locus distal to the FHIT gene. $\mathrm{Br} J$ Cancer 77: 1787-1791

Eng C, Crossey PA, Mulligan LM, Healey CS, Houghton C, Prowse A, Chew SL, Dahia PLM, O'Riordan JLH, Toledo SPA, Smith DP, Maher ER, Ponder BAJ (1995) Mutations in the RET proto-oncogene and the von Hippel-Lindau disease tumour suppressor gene in sporadic and syndromic phaeochromocytomas. J Med Genet 32: 934-937

Eng C, Smith DP, Mulligan LM, Nagai MA, Healey CS, Ponder MA, Gardner E, Scheumann GF, Jackson CE, Tunnacliffe A (1994) Point mutation within the tyrosine kinase domain of the RET proto-oncogene in multiple endocrine neoplasia type $2 \mathrm{~B}$ and related sporadic tumours. Hum Mol Genet 3: 237-241

Eng C, Kiuru M, Fernandez MJ, Aaltonen LA (2003) A role for mitochondrial enzymes in inherited neoplasia and beyond. Nat Rev Cancer 3: $193-202$

Foster K, Prowse A, van den Berg A, Fleming S, Hulsbeek MM, Crossey PA, Richards FM, Cairns P, Affara NA, Ferguson-Smith MA (1994) Somatic mutations of the von Hippel - Lindau disease tumour suppressor gene in non-familial clear cell renal carcinoma. Hum Mol Genet 12: 2169-2173

Gimenez-Roqueplo AP, Favier J, Rustin P, Rieubland C, Kerlan V, Plouin PF, Rotig A, Jeunemaitre X (2002) Functional consequences of a SDHB gene mutation in an apparently sporadic pheochromocytoma. J Clin Endocrinol Metab 87: 4771-4774

Gimm O, Armanios M, Dziema H, Neumann HP, Eng C (2000) Somatic and occult germ-line mutations in SDHD, a mitochondrial complex II gene, in nonfamilial pheochromocytoma. Cancer Res 60: 6822-6825

Gnarra JR, Tory K, Weng Y, Schmidt L, Wei MH, Li H, Latif F, Liu S, Chen F, Duh FM (1994) Mutations of the VHL tumour suppressor gene in renal carcinoma. Nat Genet 7: 85-90

Green DR, Reed JC (1998) Mitochondria and apoptosis. Science 281: $1309-1312$

Harada K, Toyooka S, Shivapurkar N, Maitra A, Reddy JL, Matta H, Miyajima K, Timmons CF, Tomlinson GE, Mastrangelo D, Hay RJ, Chaudhary PM, Gazdar AF (2002a) Deregulation of caspase 8 and 10 expression in pediatric tumors and cell lines. Cancer Res 62: 5897-5901

Harada K, Toyooka S, Maitra A, Maruyama R, Toyooka KO, Timmons CF, Tomlinson GE, Mastrangelo D, Hay RJ, Minna JD, Gazdar AF (2002b) Aberrant promoter methylation and silencing of the RASSF1A gene in pediatric tumors and cell lines. Oncogene 21: 4345-4349

Herman JG, Latif F, Weng Y, Lerman MI, Zbar B, Liu S, Samid D, Duan DS, Gnarra JR, Linehan WM (1994) Silencing of the VHL tumor-suppressor gene by DNA methylation in renal carcinoma. Proc Natl Acad Sci USA 91: $9700-9704$

Herman JG, Graff JR, Myohanen S, Nelkin BD, Baylin SB (1996) Methylation-specific PCR: a novel PCR assay for methylation status of CpG islands. Proc Natl Acad Sci USA 93: 9821-9826

Hoffman MA, Ohh M, Yang H, Klco JM, Ivan M, Kaelin Jr WG (2001) von Hippel-Lindau protein mutants linked to type $2 \mathrm{C}$ VHL disease preserve the ability to downregulate HIF. Hum Mol Genet 10: 1019-1027

Hofstra RM, Stelwagen T, Stulp RP, de Jong D, Hulsbeek M, Kamsteeg EJ, van den Berg A, Landsvater RM, Vermey A, Molenaar WM, Lips CJ, Buys $\mathrm{CH}$ (1996) Extensive mutation scanning of RET in sporadic medullary thyroid carcinoma and of RET and VHL in sporadic pheochromocytoma reveals involvement of these genes in only a minority of cases. J Clin Endocrinol Metab 81: 2881-2884

Jogi A, Abel F, Sjoberg RM, Toftgard R, Zaphiropoulos PG, Pahlman S, Martinsson T (2000) Patched 2, located in 1p32-34, is not mutated in high stage neuroblastoma tumors. Int J Oncol 16: 943-949

Leube B, Huber R, Goecke TO, Sandmann W, Royer-Pakora B (2004) SDHD mutation analysis in seven German patients with sporadic carotid body paraganglioma: one novel mutation, no Dutch founder mutation and further evidence that G12S is a polymorphism. Clin Genet 65: $61-63$

Loeb DM, Evron E, Patel CB, Sharma PM, Niranjan B, Buluwela L, Weitzman SA, Korz D, Sukumar S (2001) Wilms' tumor suppressor gene (WT1) is expressed in primary breast tumors despite tumor-specific promoter methylation. Cancer Res 61: 921-925

Maher ER, Eng C (2002) The pressure rises: update on the genetics of phaeochromocytoma. Hum Mol Genet 11: 2347-2354

Maris JM, Matthay KK (1999) Molecular biology of neuroblastoma. J Clin Oncol 17: 2264-2279

Martinsson T, Sjöberg RM, Hedborg F, Kogner P (1995) Deletion of chromosome $1 \mathrm{p}$ loci and microsatellite instability in neuroblastomas analyzed with short-tandem repeat polymorphisms. Cancer Res 55: $5681-5686$

Martinsson T, Sjöberg RM, Hallstensson K, Nordling M, Hedborg F, Kogner P (1997) Delimitation of a critical tumour suppressor region at distal $1 \mathrm{p}$ in neuroblastoma tumours. Eur J Cancer 33: 1997-2001

Maxwell PH, Wiesener MS, Chang GWW, Clifford SC, Vaux EC, Cockman ME, Wykoff CC, Pugh CW, Maher ER, Ratcliffe PJ (1999) The tumour suppressor protein VHL targets hypoxia-inducible factors for oxygendependent proteolysis. Nature 399: 271-275

Morrissey C, Martinez A, Zatyka M, Agathanggelou A, Honorio S, Astuti D, Morgan NV, Moch H, Richards FM, Kishida T, Yao M, Schraml P, Latif F, Maher ER (2001) Epigenetic inactivation of the RASSF1A 3p21.3 tumor 
suppressor gene in both clear cell and papillary renal cell carcinoma. Cancer Res 61: 7277-7281

Neumann HP, Bausch B, McWhinney SR, Bender BU, Gimm O, Franke G, Schipper J, Klisch J, Altehoefer C, Zerres K, Januszewicz A, Eng C, Smith WM, Munk R, Manz T, Glaesker S, Apel TW, Treier M, Reineke M, Walz MK, Hoang-Vu C, Brauckhoff M, Klein-Franke A, Klose P, Schmidt H, Maier-Woelfle M, Peczkowska M, Szmigielski C, Eng C (2002) Germ-line mutations in nonsyndromic pheochromocytoma. $N$ Engl J Med 346: $1459-1466$

Ohira M, Kageyama H, Mihara M, Furuta S, Machida T, Shishikura T, Takayasu H, Islam A, Nakamura Y, Takahashi M, Tomioka N, Sakiyama S, Kaneko Y, Toyoda A, Hattori M, Sakaki Y, Ohki M, Horii A, Soeda E, Inazawa J, Seki N, Kuma H, Nozawa I, Nakagawara A (2000) Identification and characterization of a 500-kb homozygously deleted region at $1 \mathrm{p} 36.2-$ p36.3 in a neuroblastoma cell line. Oncogene 19: 4302-4307
Rustin P, Chretien D, Gerard B, Bourgeron T, Rötig A, Saudubray JM, Munnich A (1994) Biochemical and molecular investigations in respiratory chain deficiencies. Clin Chim Acta 228: $35-51$

Teitz T, Wei T, Valentine MB, Vanin EF, Grenet J, Valentine VA, Behm FG, Look AT, Lahti JM, Kidd VJ (2000) Caspase 8 is deleted or silenced preferentially in childhood neuroblastomas with amplification of MYCN. Nat Med 6: $529-535$

Woodward ER, Eng C, McMahon R, Voutilainen R, Affara NA, Ponder BAJ, Maher ER (1997) Genetic predisposition to phaeochromocytoma: analysis of candidate genes GDNF, RET and VHL. Hum Mol Genet 6: $1051-1056$

Zundel W, Schindler C, Haas-Kogan D, Koong A, Kaper F, Chen E, Gottschalk AR, Ryan HE, Johnson RS, Jefferson AB, Stokoe D, Giaccia AJ (2000) Loss of PTEN facilitates HIF-1-mediated gene expression. Genes Dev 14: $391-396$ 